International Journal of Medical Anesthesiology 2018; 1(1): 13-14

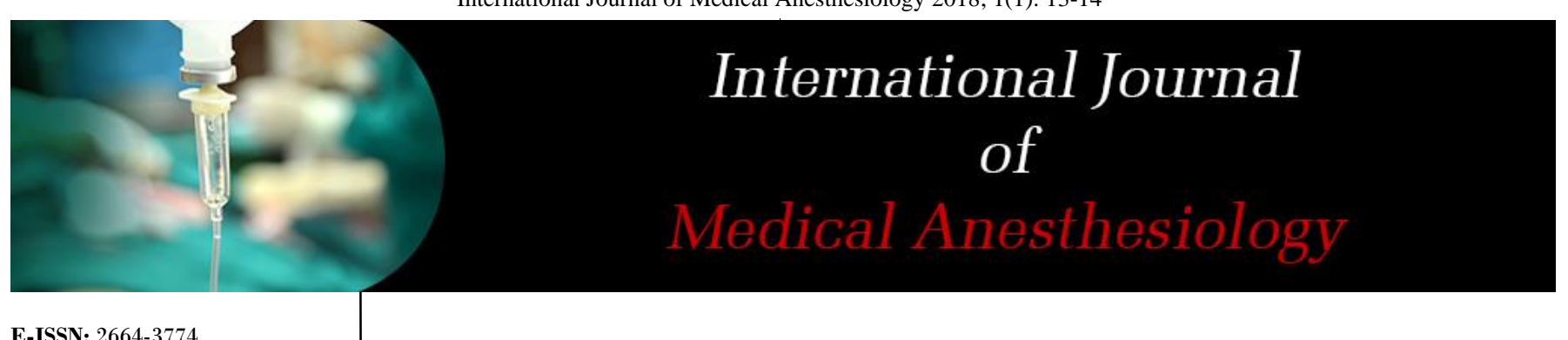

P-ISSN: 2664-3766 www.anesthesiologypaper.com IJMA 2018; 1(1): 13-14

Received: 14-11-2017

Accepted: 18-12-2017

Dr. Subhash Banerji

Department of Anesthesia, R.G. Kar Medical College and Hospital, Kolkata, India

\section{Assessment of cases of continuous spinal anaesthesia: A clinical study}

\section{Dr. Subhash Banerji}

DOI: https://doi.org/10.33545/26643766.2018.v1.i1a.5

\title{
Abstract
}

Background: Continuous spinal anaesthesia (CSA) is an under-utilized anaesthetic technique suitable for surgeries of the lower extremity, perineum and lower abdomen. The present study was conducted to determine the use of continuous spinal anaesthesia in patients.

Materials \& Methods: The present study was conducted on 126 patients with American Society of Anaesthesiologists (ASA) physical status grade I or II who underwent any surgery. Their demographic profiles, type and duration of surgery were analyzed. The success of CSA, technical evaluation and complications were assessed.

Results: Out of 126 patients, males were 62 and females were 64. Comorbidities were hypertension seen in 45, diabetes mellitus in 40, IHD in 20 and CVA in 15. The difference was significant $(P<$ 0.05). Type of surgery was knee in 48, foot in 32, hip in 35 and femur in 11 . The difference was significant $(P<0.05)$. 120 showed successful treatment and 6 had failure of anesthesia.

Conclusion: CSA is a useful anaesthetic technique and can be considered as substitute for other anesthetic solutions. There was higher success rate.

Keywords: Anaesthetic, continuous spinal anaesthesia, knee

\section{Introduction}

Continuous spinal anaesthesia (CSA) is an under-utilized anaesthetic technique suitable for surgeries of the lower extremity, perineum and lower abdomen. Continuous spinal anaesthesia (CSA) is the technique of producing and maintaining spinal anaesthesia with small doses of local anaesthetic which are injected intermittently into the subarachnoid space via an indwelling catheter ${ }^{[1]}$.

CSA has several advantages over a single- shot spinal anaesthesia (SSA) and continuous epidural anaesthesia (CEA), such as the ability to administer small, titrated and incremental doses of local anaesthetics (LA) through the catheter that may provide haemodynamic stability and the ability to achieve adequate level of dense block for indefinite duration ${ }^{22]}$. When CSA was reintroduced in the mid 1980s, the advantages described were: excellent control of segmental spread and duration; effectiveness of small doses of local anaesthetic; and decreased risk of cardiovascular side effects. The incidence of PDPH also seemed low, especially in elderly patients ${ }^{[3]}$.

There is debate regarding usefulness of regional and spinal anesthesia in cesarean section. spinal anaesthesia (SA) is now the technique of choice for CS. Although SA is generally well tolerated, it is still associated with considerable side effects, the most common of which is maternal hypotension, potentially endangering both mother and child ${ }^{[4]}$. The present study was conducted to determine the use of continuous spinal anaesthesia in patients.

\section{Materials \& Methods}

The present study was conducted in the department of Anesthesiology. It comprised of 126 patients with American Society of Anaesthesiologists' (ASA) physical status grade I or II who underwent any surgery. The study protocol was approved prior to the commencement of study. All patients were informed regarding the study and written consent was obtained.

General information such as name, age etc. was recorded in performa. Their demographic profiles, type and duration of surgery were analyzed. The success of CSA, technical evaluation and complications were assessed. Results were subjected to statistical analysis. P value less than 0.05 was considered significant.

Dr. Subhash Banerji Department of Anesthesia, R.G. Kar Medical College and Hospital, Kolkata, India 


\section{Results}

Table I: Distribution of patients

\begin{tabular}{|c|c|c|}
\hline \multicolumn{3}{|c|}{ Total- 126 } \\
\hline Groups & Male & Female \\
\hline Number & 62 & 64 \\
\hline
\end{tabular}

Table I shows that out of 126 patients, males were 62 and females were 64 .

Table II: Assessment of parameters

\begin{tabular}{|c|c|c|}
\hline Parameters & Number & \multirow{2}{*}{ P value } \\
\hline Comorbidities & & \multirow{2}{*}{0.04} \\
\hline Hypertension & 45 & \\
\hline Diabetes mellitus & 40 & \\
\hline IHD & 20 & \\
\hline CVA & 15 & \multirow{2}{*}{0.01} \\
\hline Type of surgery & & \\
\hline Knee & 48 & \\
\hline Foot & 32 & \\
\hline Hip & 35 & \\
\hline Femur & 11 & \\
\hline
\end{tabular}

Table II shows that comorbidities were hypertension seen in 45, diabetes mellitus in 40, IHD in 20 and CVA in 15. The difference was significant $(P<0.05)$. Type of surgery was knee in 48 , foot in 32 , hip in 35 and femur in 11 . The difference was significant $(P<0.05)$.

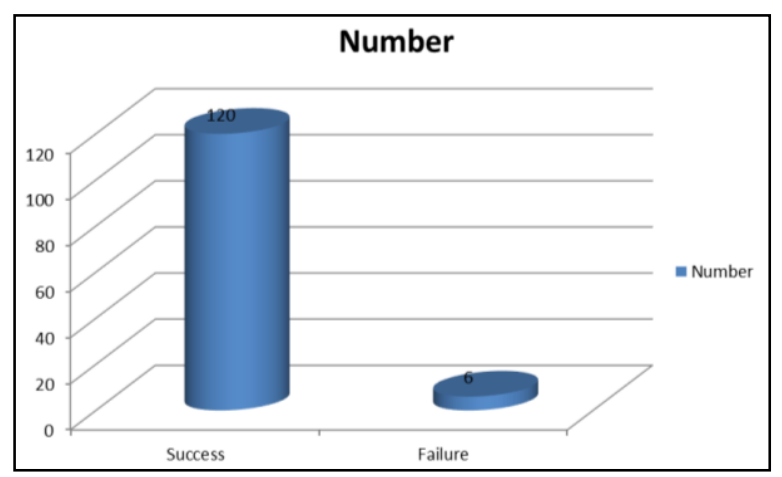

Graph I: Outcome of Continuous spinal anaesthesia

Graph I shows that 120 showed successful treatment and 6 had failure of anesthesia.

\section{Discussion}

CSA was first described by Edward Tuohy in 1944. He devised a technique of inserting a ureteral catheter 4-5 cm into the subarachnoid space via a 15-gauge Huber point needle and initiating spinal anaesthesia with incremental doses of local anaesthetic. He found that the dose of local anaesthetic used for single injection spinal anaesthesia could be reduced by $20-25 \%$ with the CSA technique ${ }^{[5]}$. He recommended it for surgery below the umbilicus and reported no increase in the incidence of PDPH compared with single injection techniques and no neurological complications. His comments on the technique are as revealing and pertinent today as they were then: "A question has been raised concerning the direction the catheter will advance in the subarachnoid space after the tip of the catheter leaves the end of the guiding needle ${ }^{[6]}$. The present study was conducted to determine the use of continuous spinal anaesthesia in patients.

In this study, out of 126 patients, males were 62 and females were 64. Hurley et al. ${ }^{[7]}$ in their study, inserted 28-gauge microcatheters in 127 parturients using continuous spinal anesthesia (CSA) for pain relief. There was a 33\% incidence of patients with postdural puncture headache (PDPH) and an $0.8 \%$ incidence of PDPH with neurologic complications in this group. The authors concluded that CSA is associated with an increased frequency of neurologic complications and should be reserved for high-risk patients.

We found that comorbidities were hypertension seen in 45 , diabetes mellitus in 40, IHD in 20 and CVA in 15. The difference was significant $(P<0.05)$. Type of surgery was knee in 48, foot in 32, hip in 35 and femur in 11. The difference was significant $(P<0.05) .120$ showed successful treatment and 6 had failure of anesthesia.

Continuous spinal anaesthesia (CSA) is an underutilised anaesthetic technique. Standl et al. ${ }^{[8]}$ conducted a study in which three hundred and eighteen patients (94\%) successfully underwent surgery using CSA. Twenty cases (6\%) had failed CSA, of which five of them had CSA insertion failure, while the rest failed to complete the operation under CSA, thus requiring conversion to general anaesthesia. Patients who have had an initial intrathecal local anaesthetic (LA) volume $\geq 1.5 \mathrm{ml}$ had higher odds interval of developing hypotension compared to those who had $<1.5 \mathrm{ml}(P<0.001)$. There were no reported post- dural puncture headache, neurological sequelae or infection.

Van Gessel et al. ${ }^{[9]}$ found that none of our patients had CSA catheter breakage, and this could be due to better practice of removing the CSA catheter with the patient's spine in a flexed position, and the slow removal of the catheter. Authors advocated that the CSA catheter should be pulled out as close to its insertion point as possible, so as not to overstretch and break the CSA catheter.

\section{Conclusion}

Authors observed that CSA is a useful anaesthetic technique and can be considered as substitute for other anesthetic solutions. There was higher success rate.

\section{References}

1. Denny NM, Selander DE. Continuous spinal anaesthesia. Br J Anaesth. 1998; 81:590-7.

2. Lux EA. Continuous spinal anesthesia for lower limb surgery: A retrospective analysis of 1212 cases. Local Reg Anesth. 2012; 5:63-7.

3. Moore JM. Continuous spinal anesthesia. Am J Ther 2009; 16:289-94.

4. Puolakka R, Haasio J, Pitkänen MT, Kallio M, Rosenberg PH. Technical aspects and postoperative sequelae of spinal and epidural anesthesia: A prospective study of 3,230 orthopedic patients. Reg Anesth Pain Med. 2000; 25:488-97.

5. Peyton PJ. Complications of continuous spinal anaesthesia. Anaesth Intensive Care. 1992; 20:417-25.

6. Denny N, Masters R, Pearson D, Read J, Sihota M, Selander D, et al. Postdural puncture headache after continuous spinal anesthesia. Anesth Analg 1987; 66:791-4.

7. Hurley RJ, Lambert DH. Continuous spinal anesthesia with a microcatheter technique: Preliminary experience. Anesth Analg. 1990; 70:97-102.

8. Standl T, Eckert S, Schulte am Esch J. Microcatheter continuous spinal anaesthesia in the post-operative period: A prospective study of its effectiveness and complications. Eur J Anaesthesiol. 1995; 12:273-9.

9. Van Gessel EF, Forster A, Gamulin Z. Continuous spinal anesthesia: Where do spinal catheters go? Anesth Analg. 1993; 76:1004-7. 